\title{
Intergenerational Mobility in Relative Educational Attainment and Health-Related Behaviours
}

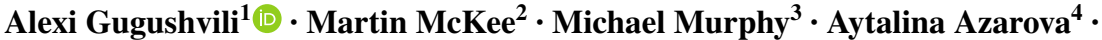 \\ Darja Irdam $^{4} \cdot$ Katarzyna Doniec $^{4} \cdot$ Lawrence King $^{4}$
}

Accepted: 28 December 2017 / Published online: 5 January 2018

(C) The Author(s) 2018. This article is an open access publication

\begin{abstract}
Research on intergenerational social mobility and health-related behaviours yields mixed findings. Depending on the direction of mobility and the type of mechanisms involved, we can expect positive or negative association between intergenerational mobility and health-related behaviours. Using data from a retrospective cohort study, conducted in more than 100 towns across Belarus, Hungary and Russia, we fit multilevel mixed-effects Poisson regressions with two measures of health-related behaviours: binge drinking and smoking. The main explanatory variable, intergenerational educational mobility is operationalised in terms of relative intergenerational educational trajectories based on the prevalence of specified qualifications in parental and offspring generations. In each country the
\end{abstract}

Alexi Gugushvili

alexi.gugushvili@spi.ox.ac.uk

Martin McKee

martin.mckee@1shtm.ac.uk

Michael Murphy

m.murphy@1se.ac.uk

Aytalina Azarova

aa872@cam.ac.uk

Darja Irdam

di232@cam.ac.uk

Katarzyna Doniec

kd353@cam.ac.uk

Lawrence King

1k285@cam.ac.uk

1 Department of Social Policy and Intervention and Nuffield College, University of Oxford, Barnett House, 32 Wellington Square, Oxford OX1 2ER, UK

2 European Centre on Health of Societies in Transition, London School of Hygiene and Tropical Medicine, London, UK

3 Department of Social Policy, London School of Economics and Political Science, London, UK

4 Department of Sociology, University of Cambridge, Cambridge, UK 
associations between intergenerational educational mobility, binge drinking and smoking was examined with incidence rate ratios and predicted probabilities, using multiply imputed dataset for missing data and controlling for important confounders of healthrelated behaviours. We find that intergenerational mobility in relative educational attainment has varying association with binge drinking and smoking and the strength and direction of these effects depend on the country of analysis, the mode of mobility, the gender of respondents and the type of health-related behaviour. Along with accumulation and Falling from Grace hypotheses of the consequences of intergenerational mobility, our findings suggest that upward educational mobility in certain instances might be linked to improved health-related behaviours.

Keywords Relative intergenerational mobility · Education · Binge drinking · Smoking · Demographic cohort study

\section{Introduction}

For most of the post-war period, parents in western countries could expect their children to far better than they did. No longer. Data from the USA show that, while $90 \%$ of children born in the 1940s earned more than their parents, that figure is falling rapidly and is now only 50\% for those born in the 1980s (Chetty et al. 2017). This has many implications for society, especially when combined with other factors, such as housing prices and pension changes, that mean that younger people now are accumulating wealth at a much lower level in the past (D'Arcy and Gardiner 2017). But what does it mean for health-related behaviours? There is a considerable body of evidence linking intergenerational social mobility with health outcomes, discussed further below (Boyle et al. 2009; Cardano et al. 2004; Dahl 1996; Faresjö et al. 1994; Hart et al. 1998, 2009; Jonsson et al. 2017; Padyab and Norberg 2014; Power et al. 1996).

One important pathway in these relationships, health-related behaviours, has not received much scholarly attention (Burrows and Nettleton 1995; Hemmingsson et al. 1999; Jefferis et al. 2004; Karvonen et al. 1999; Paavola et al. 2004). These are particularly salient in post-socialist societies where the transition has disrupted traditional intergenerational relationships (Gugushvili 2015, 2016a, b, 2017a; Lippényi and Gerber 2016; Titma and Roots 2006) and where certain health-related behaviours play a major role in population health (Bobak et al. 1999; Cockerham et al. 2006; Fiatal et al. 2016; Gilmore et al. 2001). While there is sociological research on the trends and correlates of intergenerational social mobility in post-socialist contexts and public health literature on the correlates of drinking and smoking, virtually no studies we are aware of enquire into the links between intergenerational social mobility and health-related behaviours.

The lack of empirical research itself justifies our study. However, another rationale stems from recent article by Campos-Matos and Kawachi (2015) in which they find that the association between intergenerational social mobility, assessed by educational attainment, and self-rated health varies among different welfare regimes in Europe. Their findings suggest that upward intergenerational mobility in the former Soviet Union and other post-socialist societies is associated with lower risk of reporting bad or very bad self-rated health when compared to those who remained intergenerationally non-mobile. Indeed, it was only in the former Soviet republics that the differences in self-related health between socially mobile and non-mobile groups were significant. Here we use an alternative data 
set, methods and operationalization of intergenerational educational mobility to explore possible pathways between intergenerational mobility and health, via their health-related behaviours such as binge drinking and smoking. We do so in three post-socialist societies, Belarus, Hungary and Russia.

\section{Theoretical Considerations}

There is no unified theory to suggest how intergenerational social mobility affects healthrelated behaviours as the studies testing the links between the two are virtually non-existent. Nonetheless, numerous scholars in sociology and public health have investigated health consequences of intergenerational social mobility experience (Heraclides and Brunner 2010; Houle and Martin 2011; Iveson and Deary 2017; Nicklett and Burgard 2009). Depending on the direction of mobility, upward versus downward, and the type of mechanisms involved, including accumulation of advantages or disadvantages, improvements in living standards, psychosocial effects and social learning, scholars expect to find positive or negative consequences of intergenerational mobility on health outcomes. Most existing hypotheses in this area of research emphasize the role of stress related to social mobility as the main causal channel affecting health of socially mobile individuals. On the other hand, it is well documented that stress among individuals is strongly related to their drinking and smoking patterns (Ayer et al. 2011; Childs and de Wit 2010; Kouvonen 2005; Steptoe et al. 1996; Zhang and Hwang 2007). This might suggest that intergenerational social mobility affects individuals' stress levels which in turn could be related to health-related behaviours. Consequently, both stress and health-related behaviours might influence individuals' health. These associations are illustrated in Fig. 1 which also shows that they are direct effects of individuals' social origin and destination socioeconomic position on their health.

The links between intergenerational mobility and health-related behaviours can be also understood in terms of an accumulation model of health outcomes, which sees individuals' health at any one time as the consequence of cumulative exposures to biological, psychosocial and material circumstances up to that time (Bartley and Plewis 2007). If we again refer to the links between intergenerational social mobility and health, numerous studies find that upwardly mobile individuals have better health than those in the social environment

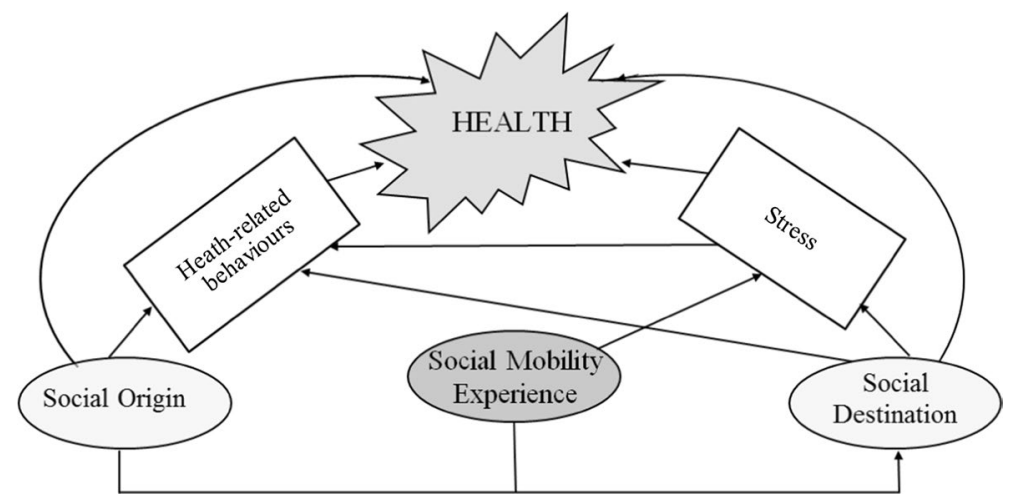

Fig. 1 Theoretical model linking intergenerational mobility and individuals' health. Source: Authors' interpretation 
they leave behind but poorer health than those in the adult social environment they join (Blane et al. 1993; Boyle et al. 2009). The accumulation model implies that, after controlling for social origins, moving upward (downward) by virtue of social mobility reduces (increases) harmful exposures compared to non-mobile individuals, which in turn leads to better (worse) health outcomes. The same logic applies to individuals' health-related behaviours. The large social gradient in hazardous drinking and smoking is well established (Marmot 2005) but these behaviours are, to varying degrees, conditioned by behaviours in early life (Jefferis et al. 2003). For instance, those who do not initiate smoking in adolescence are very unlikely to do so later (Giovino et al. 1995).

Although the accumulation perspective is an important mechanism, psychosocial effects are thought to be the main channel which links intergenerational social mobility and healthrelated behaviours. The dissociative thesis, probably the most widely tested hypothesis in the literature on consequences of social mobility, views moving away from one's social origins as disruptive because mobile individuals have acquired their worldviews in one type of environment but must confront different sets of attitudes and values in another (Daenekindt 2016; Jonsson et al. 2017). Not being fully integrated in either social environment, these mobile individuals may feel less satisfied with life, experience increased distress, and consequently engage in negative health-related behaviours (Houle 2011). Linked to this is the Falling from Grace hypothesis (Newman 1999), whereby downward social mobility, in addition to any specific consequences of low socio-economic status, elevates levels of distress and feelings of insecurity as individuals find themselves less able to direct their own lives than they had expected when growing up which consequently also influences their health-related behaviours.

The main shortcoming of the dissociative and the Falling from Grace hypotheses is their prediction that both upward and downward intergenerational social mobility are associated with feelings of anxiety, strain, and distress without considering possible positive psychosocial outcomes of social mobility. Thus, several studies do not find significant associations between intergenerational mobility and health or even find that upward social mobility can lead to positive health-related behaviours and better health outcomes (Hemmingsson et al. 1999; Houle 2011). There are specific reasons why upwardly mobile individuals might have better health-related behaviours than comparable non-mobile groups. An improvement in socioeconomic status could have a protective effect on individuals' psychological wellbeing by, for example, generating confidence and a sense of control of one's own life (Poulton et al. 2002). It is also possible that upwardly mobile individuals might seek to distance themselves from their social origins by enthusiastically following the dominant lifestyle and health-related behaviours associated with their new social environment (Burrows and Nettleton 1995).

The aim of this article is to test which of the described alternative hypotheses most appropriately explains an association between intergenerational mobility and health-related behaviours, if there is any, in three post-socialist societies. We do this using a newly generated data set which includes information on respondents' educational attainment and their drinking and smoking behaviours and that of their parents. In addition to investigating the association of intergenerational social mobility and health-related behaviours, this article also makes a methodological and conceptual contribution to the literature. First, recent social mobility scholarship increasingly recognises that, in order to understand the net effect of intergenerational educational mobility, individuals' and their parents education has to be viewed and operationalised in relative rather than absolute terms, that is, as a positional good, taking into account the relative prevalence of qualifications in parental and offspring generations (Goldthorpe 2014; Gugushvili et al. 2017). Second, most existing 
studies in public health and social epidemiology look at the implications of intergenerational social mobility on health-related behaviours of young people, while social mobility literature suggests that individuals only achieve a mature socio-economic status later in life (Bukodi and Goldthorpe 2016). Our dataset, described in detail in the next section, consists of individuals aged 40 and above, offering an advantage over existing studies which examine social mobility among those who have yet to reach maturity in their socio-economic status.

\section{Methods}

\subsection{Dataset}

Our analyses are based on the PrivMort data set, collected within a multi-disciplinary project funded by the European Research Council whose main objective is to investigate the post-Communist morbidity and mortality crisis using a multi-level retrospective cohort study (Irdam et al. 2016). PrivMort data are from original surveys in 20, 52 and 30 towns respectively in Belarus, Hungary and the European part of Russia. We conducted surveys in Belarus and the European part of Russia mainly because the post-Communist health and mortality crisis was especially severe in these regions of the former Soviet Union. Belarus and most of European Russia (see below) have relatively homogeneous populations, sharing similar socio-economic, cultural and religious characteristics, including infamously high alcohol and tobacco consumption, especially among men (Cockerham 2000; Gilmore et al. 2001; Pomerleau et al. 2008). However, the two countries have experienced a different pace and type of transition. On the other hand, Hungary allows investigation of the transitional health crisis in a non-Soviet post-communist country. Like in Belarus and Russia, life expectancy in Hungary declined significantly at the beginning of the transition and the country also has a high level of alcohol consumption, particularly home-distilled liquors (pálinka) (Szucs et al. 2005), as well as high levels of smoking (Forey et al. 2013).

During the first stage of the project, PrivMort collected basic economic, demographic and enterprise-level data on all towns of Russia with 5000-100,000 inhabitants in the European part of the country, excluding the regions of the North Caucasus. These regions were excluded as some have substantial Muslim populations, with dietary and alcohol consumption very different from the rest of Russia, which might potentially confound health outcomes. A set of 30 towns was selected from the pool of 539 using propensity score matching for the likelihood of experiencing rapid privatization. Propensity scores were calculated on the basis of the pre-transition demographic and socio-economic conditions in the towns. Since one of the main goals of PrivMort project was to identify the health consequences of rapid privatisation, ten mono-industrial towns (defined as having a single industrial enterprise providing employment for at least $7.5 \%$ of the total population) with rapid privatization (where 90 or more per cent of state shares were privatized within two consecutive years) were matched to ten mono-industrial towns with slow privatization (where less than $50 \%$ of state shares were privatized within two consecutive years). Additionally, a group of five multi-industrial towns (where employment is distributed proportionally among several industrial enterprises) was selected closely matching an additional five mono-industrial towns.

In Belarus, as in Russia, only towns with 5000-100,000 inhabitants were included. Out of the pool of 96 towns which fall into this category, all 11 mono-towns were selected 
for survey data collection. Then, 9 multi-slow towns in Belarus were matched to existing fifteen mono-fast towns in Russia. In Hungary, we selected all towns with 5000-100,000 inhabitants where industrial employment exceeded $30 \%$ at the beginning of the 1990s. As in the Russian and Belarusian samples, towns within commuting distance to the capital were excluded. 52 towns were randomly selected from a total sample of 83 towns in Hungary matching the selection criteria.

In the selected towns, houses/apartments were randomly chosen using the random walk method between June 2014 and April 2015, and interviewers of survey organisations VCIOM, SIMST and TARKI in Russia, Belarus and Hungary respectively, conducted faceto-face interviews. Only one respondent was selected from each household. To be included, a potential respondent had to be born before 1972, and have at least one family member (parents, siblings, or husbands) who lived in the same town for a prolonged period of time during and after the transition. This criterion ensured that a respondent had reached working age by 1991. Overall 16,000, 24,072 and 24,069 individuals were interviewed in Belarus, Hungary and Russia. In addition to information collected on respondents' socio-demographic, socio-economic and health-related behaviours, PrivMort acquired data on their fathers' and mothers' educational attainment, used to derive the intergenerational educational mobility variable employed in our analysis of respondents' likelihood to binge drink and smoke.

To compensate for missing data on paternal education, which was not reported by some respondents (13.7, 16.6 and in 19.5\%, respectively, in Belarus, Hungary and Russia) we used multiple imputation via the MICE (Multiple Imputation using Chained Equations) package in Stata, version 14, allowing for twenty sets of multiple imputations and combining them using Rubin's (1987) rules. Although we stratify our analyses by gender, in all countries women are overrepresented in the data set-76.3\% in Belarus, $65.8 \%$ in Hungary and $77.8 \%$ in Russia. The latter is a result of significantly more men being away from their households as well as men having higher mortality rates than women in these countries (Gugushvili 2016a). More details concerning the selection of towns, respondents and other aspects of the PrivMort methodology are given elsewhere (Azarova et al. 2017; Irdam et al. 2016).

\subsection{Outcome Variables}

We use two measures of health-related behaviour as our outcome variables-binge drinking and smoking. Binge drinking is operationalised as a dummy variable which takes value of 1 if respondents' drink up to half a litre of vodka (in Russia and Belarus) or brandy ((pálinka) in Hungary) or two bottles of wine or 5 bottles of beer in one evening at least once a month or more often. Our dummy variable for smoking captures those individuals who report being regular smokers as opposed to individuals who have never smoked or used to smoke but have quit. Table 1 shows the frequencies of binge drinking and smoking across Belarus, Hungary and Russia. In the post-Soviet countries about one-fourth of men report binge drinking in the past month, while in Hungary this is about $13 \%$. Binge drinking among women is also more prevalent in Russia (5.2\%) and Belarus (6.6\%) than in Hungary (2.2\%). Russia and Belarus are very similar in terms of the prevalence of current smokers among men (about 40\%), while Hungary has much higher rate of smoking among women (15.2\%) than Belarus (3.6\%) and Russia (4.5\%). 
Table 1 Descriptive statistics of dependent variables, \%. Source: Authors' calculations based on the PrivMort data set

\begin{tabular}{|c|c|c|c|c|c|c|}
\hline & \multicolumn{3}{|l|}{ Men } & \multicolumn{3}{|l|}{ Women } \\
\hline & Belarus & Hungary & Russia & Belarus & Hungary & Russia \\
\hline \multicolumn{7}{|c|}{ Binge drinking } \\
\hline Yes & 24.5 & 12.5 & 26.4 & 6.6 & 2.2 & 5.2 \\
\hline No & 75.5 & 87.5 & 73.6 & 93.4 & 97.8 & 94.8 \\
\hline In totals & 100.0 & 100.0 & 100.0 & 100.0 & 100.0 & 100.0 \\
\hline \multicolumn{7}{|l|}{ Smoking } \\
\hline Yes & 40.3 & 29.4 & 42.9 & 3.6 & 15.2 & 4.5 \\
\hline No & 59.7 & 70.6 & 57.1 & 96.4 & 84.8 & 95.5 \\
\hline In totals & 100.0 & 100.0 & 100.0 & 100.0 & 100.0 & 100.0 \\
\hline
\end{tabular}

\subsection{Intergenerational Educational Mobility}

In order to generate the main independent variable used in this study, intergenerational mobility in educational status, we use the PrivMort variables on the highest level of education respondents and their parents attained. In both instances the level of education is classified into eight categories: (a) incomplete elementary; (b) complete elementary or incomplete secondary; (c) complete academic secondary; (d) complete vocational secondary without general high school leaving exam; (e) complete vocational secondary with general high school leaving exam; (f) incomplete higher; (g) complete vocational higher; and (h) complete academic higher.

The most straightforward way of generating a variable of intergenerational educational mobility would be to compare the formal level of educational attainment between parents and their children, but this approach would ignore the continuous improvement over time of levels of education in socialist and post-socialist societies (Gerber and Hout 1995; Higher Education in Europe 1977) and its implications for inequality (Raftery and Hout 1993; Shkolnikov 2006).

Education, like other markers of status, is believed to be a positional good, which means that the value of educational qualifications diminishes in proportion to the number of individuals who acquire them (Breen et al. 2009). In addition, if education serves as one of the main characteristics for employers in selecting employees, the quality of jobs that are available to individuals will depend not only on how much education they have acquired, but also on how well educated they are relative to others in the labour pool (Goldthorpe 2014). In terms of health-related behaviours, subjective socio-economic status has been shown to be an important covariate of drinking and smoking (Reitzel et al. 2010; Ritterman et al. 2009). Therefore, intergenerational educational mobility in relative terms could be more appropriate than absolute educational mobility in capturing intergenerational changes in position in social hierarchy and the resultant consequences for health-related behaviours.

To derive the measure of intergenerational educational mobility, we generate relative educational attainment separately for fathers and mothers by creating the approximate tertiles of relative educational level with the following two-step procedure (see Gugushvili et al. 2017). First, based on the distribution of attained education in each of the following birth-cohorts-born before 1905, in 1906-1915, 1916-1925, 1926-1935, 1936-1945 and 1946-1954 - we divide education into approximate tertiles in each group. Second, we use 
Table 2 Relative education tertiles of parents and respondents, \%. Source: Authors' calculations based on the PrivMort data set

\begin{tabular}{|c|c|c|c|c|c|c|}
\hline \multirow[t]{2}{*}{ Tertile } & \multicolumn{2}{|l|}{ Belarus } & \multicolumn{2}{|c|}{ Hungary } & \multicolumn{2}{|l|}{ Russia } \\
\hline & Parents & Respondents & Parents & Respondents & Parents & Respondents \\
\hline \multicolumn{7}{|l|}{ Men } \\
\hline Bottom & 52.3 & 46.3 & 45.5 & 47.0 & 47.7 & 43.8 \\
\hline Middle & 17.0 & 33.6 & 29.6 & 31.7 & 21.1 & 39.0 \\
\hline Top & 30.7 & 20.1 & 24.9 & 21.2 & 31.3 & 17.2 \\
\hline In total & 100.0 & 100.0 & 100.0 & 100.0 & 100.0 & 100.0 \\
\hline \multicolumn{7}{|l|}{ Women } \\
\hline Bottom & 66.0 & 46.6 & 51.3 & 63.3 & 57.1 & 43.5 \\
\hline Middle & 13.0 & 35.2 & 28.9 & 21.0 & 19.0 & 41.6 \\
\hline Top & 21.0 & 18.2 & 19.8 & 15.7 & 23.9 & 15.0 \\
\hline In total & 100.0 & 100.0 & 100.0 & 100.0 & 100.0 & 100.0 \\
\hline
\end{tabular}

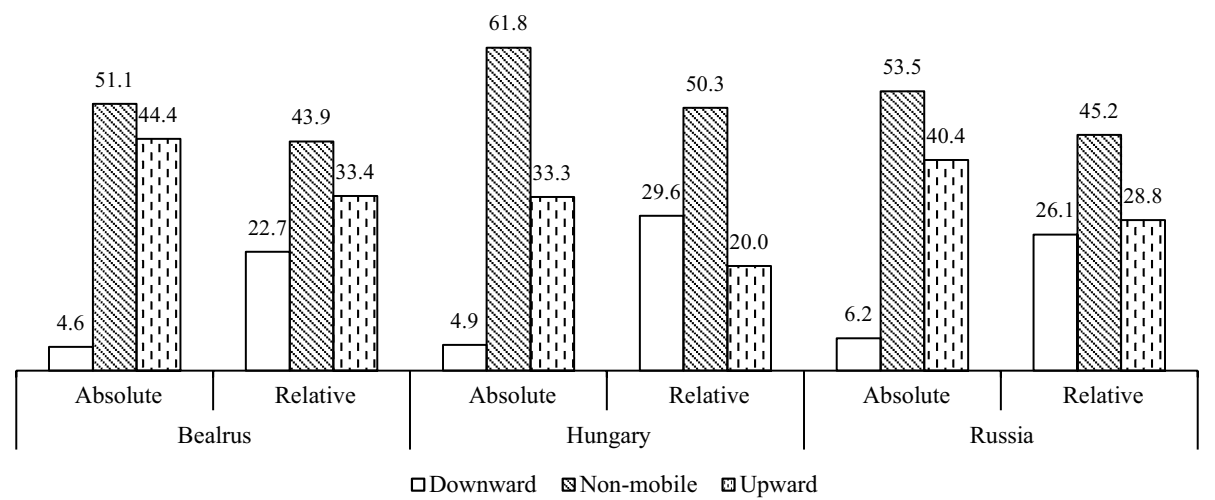

Fig. 2 Comparing absolute and relative intergenerational educational mobility in Belarus, Hungary and Russia, \%. Source: Authors' calculations based on the PrivMort data set

these variables to generate a single measure of educational attainment shown in Table 2, employing the "dominance" method, which defines the indicator of parental education as the highest level of father or mother (Erikson 2006).

For respondents' educational attainment we use the same procedure as described for their parents, but in this case relative tertiles are calculated separately for five age groups-40-50, 51-60, 61-70, 71-80 and more than 80. The distribution of tertile frequencies for respondents are shown in Table 2. In all countries, the largest tertiles are the bottom ones, while about $20 \%$ of respondents are in the top educational tertiles. The latter can be explained by the higher prevalence of primary and vocational education in comparison to tertiary education in the Belarus, Hungary and Russia.

In Fig. 2 we classify respondents as upwardly (downwardly) mobile if they are in a higher (lower) tertile of education attainment than their parents; the remaining respondents are treated as non-mobile. For brevity of presentation, we pool data for both genders and compare our relative education mobility measure with the absolute education mobility measure. The latter is based on the simple comparison of respondents' and their parents' 
formal educational attainment without considering the relative prevalence of these qualifications. It is clear that in all three countries substantially more individuals attained higher levels of formal education than their parents-more than two-fifths in Belarus and Russia and one-third in Hungary. However, when it comes to relative mobility, upwardly mobile, downwardly mobile and non-mobile individuals are much more equally distributed. The lowest mobility is observed in Hungary which is in line with the recent findings on the rigidity of intergenerational status reproduction in this country (Bukodi et al. 2017; Gugushvili 2017b).

\subsection{Analytic Strategy}

In order to detect the effect of intergenerational educational mobility, we identify those respondents in the bottom, the middle and the top educational tertiles who are upwardly mobile, downwardly mobile and non-mobile. We investigate how far specific mobility trajectories are associated with binge drinking and smoking. For this purpose, we construct an educational mobility variable by cross-tabulating the respondents' and their parents' educational attainment in nine trajectories (see Li et al. 2008): (1) the stable bottom educational tertile, (2) downwardly mobile from the middle to the bottom educational tertile; (3) downwardly mobile from the top to the bottom educational tertile; (4) upwardly mobile from the bottom to the middle educational tertile; (5) the stable middle educational tertile; (6) downwardly mobile from the top to the middle educational tertile; (7) upwardly mobile from the bottom to the top educational tertile; (8) upwardly mobile from the middle to the top educational tertile; (9) the stable top educational tertile. As Table 3 indicates the largest group of respondents are non-mobile individuals in the bottom educational tertile, but upwardly mobile individuals in the middle educational tertile also constitute a sizable mobility trajectory in all considered societies.

Our analytical strategy implies that when the results are reported as incidence rate ratios the reference categories include non-mobile individuals in the bottom, the middle and the

Table 3 Intergenerational educational trajectories in Belarus, Hungary and Russia, \%. Source: Authors' calculations based on the PrivMort data set

\begin{tabular}{|c|c|c|c|c|c|c|}
\hline \multirow[t]{2}{*}{ Mobility trajectories } & \multicolumn{3}{|l|}{ Men } & \multicolumn{3}{|l|}{ Women } \\
\hline & Belarus & Hungary & Russia & Belarus & Hungary & Russia \\
\hline \multicolumn{7}{|l|}{ Bottom tertile } \\
\hline Parent $1 \mathrm{st} \rightarrow$ respondent $1 \mathrm{st}$ & 26.5 & 27.4 & 26.1 & 34.4 & 38.8 & 30.8 \\
\hline Parent 2 nd $\rightarrow$ respondent 1 st & 8.9 & 12.9 & 8.8 & 5.6 & 17.2 & 6.8 \\
\hline Parent 3 rd $\rightarrow$ respondent 1 st & 11.0 & 6.7 & 8.9 & 6.6 & 7.2 & 5.8 \\
\hline \multicolumn{7}{|l|}{ Middle tertile } \\
\hline Parent 1 st $\rightarrow$ respondent 2 nd & 18.4 & 13.1 & 16.5 & 22.6 & 8.5 & 21.1 \\
\hline Parent 2 nd $\rightarrow$ respondent 2 nd & 4.4 & 10.1 & 8.6 & 4.4 & 6.6 & 8.7 \\
\hline Parent 3 rd $\rightarrow$ respondent 2 nd & 10.6 & 8.6 & 13.9 & 8.1 & 5.9 & 11.8 \\
\hline \multicolumn{7}{|l|}{ Top tertile } \\
\hline Parent 1 st $\rightarrow$ respondent 3 rd & 7.5 & 5.0 & 5.1 & 9.0 & 4.1 & 5.3 \\
\hline Parent 2 nd $\rightarrow$ respondent 3 rd & 3.6 & 6.6 & 3.7 & 3.0 & 5.0 & 3.5 \\
\hline Parent 3rd $\rightarrow$ respondent 3rd & 9.1 & 9.6 & 8.5 & 6.3 & 6.6 & 6.3 \\
\hline In total & 100.0 & 100.0 & 100.0 & 100.0 & 100.0 & 100.0 \\
\hline
\end{tabular}


top educational tertiles. In practice, this means that we run three separate regressions each time, changing only the reference category which does not affect the overall model fit or the relative values of the regression coefficients for other variables included in the models. In the remainder of this article, we use terms "intergenerational educational mobility" and "educational trajectories" interchangeably. To disentangle the effect of intergenerational educational mobility from parental and respondents' own attainment, we could alternatively use diagonal reference models (Daenekindt 2016; Houle and Martin 2011; Liang and $\mathrm{Lu} 2014$ ), but it has been demonstrated that the latter approach produces very similar results to those derived from intergenerational mobility trajectories (Chan 2017). In addition, the substantive interpretation of diagonal reference models is less straightforward than identifying the consequences of mobility for individuals with different intergenerational trajectories.

Since both of our dependent variables have a binary form, for each country we fit twolevel random-intercept mixed-effects Poisson regressions using the "mepoisson" command in the statistical software Stata, version 14. In this hierarchical model specification, which is widely used in social science research, we identify the group structure for the random effects at the town level separately in Belarus, Hungary and Russia. We do not include specific contextual variables on the town level primarily because of comparability of measures derived from different statistical sources. We run models separately for men and women as there are substantial differences in drinking and smoking in the considered societies. We also calculate post-estimation predicted probabilities of binge drinking and smoking with corresponding 95\% CIs for individuals in all nine mobility trajectories (King et al. 2012).

\subsection{Covariates}

Our regression models, in addition to accounting for intergenerational mobility in educational attainment and corresponding levels of parental and individuals' education, control for important covariates which have been identified in the previous research to be associated with binge drinking and smoking (Burrows and Nettleton 1995; Cockerham et al. 2006; Hart et al. 1998; Hemmingsson et al. 1999; Jefferis et al. 2004; Johnson et al. 2010; Levin 1994; Paavola et al. 2004; Pomerleau et al. 2004; Tumen and Zeydanli 2014), as shown in Table 4. Respondents' age is categorized into five groups: 40-50, 51-60, 61-70, 71-80, and those older than 80. Marital status is operationalised with single, married, separated/divorced and widowed individuals. To account for socio-economic status we consider private ownership of a house/flat and a car by the household where respondents live. The latter two variables take a value of 3 if their households owned a house/flat or a car throughout three decades in the 1980s, 1990s, and 2000s and a value 0 if not owned in the corresponding periods. Respondents' labour market status is operationalised by being in or out of work at interview. We account for individuals' supervisory responsibilities and self-employment/entrepreneurship status in the 1990s-2000s. Lastly, we also control for respondents' religious denomination as some religions sanction particular behaviours related to alcohol and tobacco consumption. Descriptive statistics indicates that for most of the control variables Belarus and Russia are similar to each other, while Hungary stands out with its higher ownership of cars and private apartments and its lower prevalence of working individuals and those with supervisory status. 
Table 4 Descriptive statistics of independent variables, \%. Source: Authors' calculations based on the PrivMort data set

\begin{tabular}{|c|c|c|c|c|c|c|}
\hline & \multicolumn{3}{|l|}{ Men } & \multicolumn{3}{|l|}{ Women } \\
\hline & Belarus & Hungary & Russia & Belarus & Hungary & Russia \\
\hline \multicolumn{7}{|l|}{ Respondents' age } \\
\hline $40-50$ & 30.5 & 20.9 & 26.7 & 19.8 & 16.3 & 18.0 \\
\hline $51-60$ & 30.1 & 24.0 & 31.6 & 27.8 & 22.8 & 27.3 \\
\hline $61-70$ & 22.2 & 26.5 & 25.1 & 25.3 & 28.4 & 28.6 \\
\hline $71-80$ & 12.1 & 20.1 & 12.6 & 19.7 & 23.2 & 19.6 \\
\hline 80 and over & 5.1 & 8.5 & 4.0 & 7.5 & 9.3 & 6.6 \\
\hline Total & 100.0 & 100.0 & 100.0 & 100.0 & 100.0 & 100.0 \\
\hline \multicolumn{7}{|l|}{ Marital status } \\
\hline Single & 5.0 & 8.7 & 6.4 & 2.5 & 3.9 & 3.8 \\
\hline Married & 69.6 & 60.4 & 70.6 & 50.6 & 46.8 & 50.3 \\
\hline Separated/divorced & 14.7 & 15.8 & 12.5 & 11.9 & 14.1 & 11.8 \\
\hline Widow/widower & 10.8 & 15.2 & 10.5 & 35.0 & 35.2 & 34.2 \\
\hline In total & 100.0 & 100.0 & 100.0 & 100.0 & 100.0 & 100.0 \\
\hline \multicolumn{7}{|c|}{ Owning house/flat in $1980 \mathrm{~s}-2000 \mathrm{~s}$} \\
\hline Not at all & 5.4 & 1.8 & 6.1 & 4.5 & 2.2 & 6.1 \\
\hline Only in one decade & 4.7 & 1.6 & 2.4 & 3.3 & 1.5 & 2.8 \\
\hline In two decades & 11.7 & 4.6 & 8.8 & 11.6 & 4.8 & 9.4 \\
\hline Throughout & 78.2 & 92.1 & 82.7 & 80.5 & 91.5 & 81.8 \\
\hline In total & 100.0 & 100.0 & 100.0 & 100.0 & 100.0 & 100.0 \\
\hline \multicolumn{7}{|c|}{ Owning car in 1980s-2000s } \\
\hline Not at all & 39.9 & 34.3 & 44.6 & 58.2 & 45.9 & 62.2 \\
\hline Only in one decade & 17.6 & 9.0 & 15.9 & 13.7 & 9.7 & 12.6 \\
\hline In two decades & 21.3 & 16.2 & 18.0 & 14.6 & 14.5 & 12.3 \\
\hline Throughout & 21.2 & 40.5 & 21.5 & 13.5 & 29.9 & 12.9 \\
\hline In total & 100.0 & 100.0 & 100.0 & 100.0 & 100.0 & 100.0 \\
\hline \multicolumn{7}{|l|}{ Work status } \\
\hline Working & 55.6 & 37.6 & 49.6 & 37.4 & 27.0 & 35.3 \\
\hline Not working & 44.4 & 62.4 & 50.4 & 62.6 & 73.0 & 64.7 \\
\hline In total & 100.0 & 100.0 & 100.0 & 100.0 & 100.0 & 100.0 \\
\hline \multicolumn{7}{|c|}{ Supervisory responsibilities } \\
\hline Yes & 24.3 & 9.6 & 23.5 & 19.3 & 6.6 & 19.7 \\
\hline No & 75.7 & 90.4 & 76.5 & 80.7 & 93.4 & 80.3 \\
\hline In total & 100.0 & 100.0 & 100.0 & 100.0 & 100.0 & 100.0 \\
\hline \multicolumn{7}{|l|}{ Self-employment } \\
\hline Yes & 6.6 & 3.7 & 5.8 & 3.0 & 1.9 & 2.8 \\
\hline No & 93.4 & 96.3 & 94.3 & 97.1 & 98.1 & 97.2 \\
\hline In total & 100.0 & 100.0 & 100.0 & 100.0 & 100.0 & 100.0 \\
\hline
\end{tabular}


Table 4 (continued)

\begin{tabular}{|c|c|c|c|c|c|c|}
\hline & \multicolumn{3}{|l|}{ Men } & \multicolumn{3}{|l|}{ Women } \\
\hline & Belarus & Hungary & Russia & Belarus & Hungary & Russia \\
\hline \multicolumn{7}{|l|}{ Religious denomination } \\
\hline Orthodox & 83.3 & - & 89.3 & 84.9 & - & 95.0 \\
\hline Non-Orthodox Christian & 11.7 & 84.9 & 1.1 & 13.7 & 90.7 & 1.0 \\
\hline Muslim & 0.3 & - & 1.1 & 0.1 & - & 1.2 \\
\hline Other & 4.7 & 15.1 & 8.5 & 1.3 & 9.3 & 2.8 \\
\hline In total & 100.0 & 100.0 & 100.0 & 100.0 & 100.0 & 100.0 \\
\hline
\end{tabular}

\section{Results}

\subsection{Baseline Analysis}

The results presented in Tables 5 and 6 are adjusted for respondents' age and indicate that for both genders the standard deviation of the intercepts across towns in Belarus, Hungary and Russia is higher for binge drinking than is the case for smoking. This suggests that towns where respondents were interviewed are less similar to each other in terms of binge drinking than they are in terms of smoking. The interclass correlation coefficients (ICC) also show that nesting individuals in towns account for up to 12 and $20 \%$ variance in binge drinking, respectively for women and men even after controlling for individual-level predictors, while for smoking the ICC is less than 5\%, except for women in Russia where the value is $9 \%$.

Before discussing the implications of social mobility for binge drinking and smoking, we briefly review the results for our confounding variables. As regards marital status' association with the dependent variables, separated and divorced men have consistently higher incidence rate ratios of engaging in both negative health-related behaviours, while single and widowed women are also more likely to be current smokers. For men, living in their privately owned apartment/house in the 1980s-2000s reduces the risk of binge drinking and smoking only in Hungary, while among women it is associated with a reduced likelihood of binge drinking in all settings. For both men and women, having a car is associated with reduced smoking in Hungary and Russia. Working women in Belarus and working men in Belarus and Hungary are significantly less likely to smoke. Supervisory status is associated with higher risk of binge drinking among Hungarian women and lower risk of smoking among men in all included countries. Self-employment is related to lower levels of smoking among Belarusian men, but higher levels among Belarusian and Russian women. Among non-Christian Hungarians, men appear to have both higher incidence rate ratios of binge drinking and smoking, while non-Orthodox Christian men in Belarus have lower risk of smoking than Orthodox Christians. Lastly, non-Christian Hungarian women have higher likelihood of negative health-related behaviours and non-Christian women in Russia are also more likely to smoke.

Moving to the findings related to intergenerational educational mobility, results from multilevel mixed-effects Poisson regressions in Tables 5 and 6 demonstrate that, controlling for other confounders, intergenerational educational mobility does not have consistent associations with the health-related behaviours in all countries, although intergenerationally mobile individuals do, in some instances, differ from non-mobile individuals. Men 


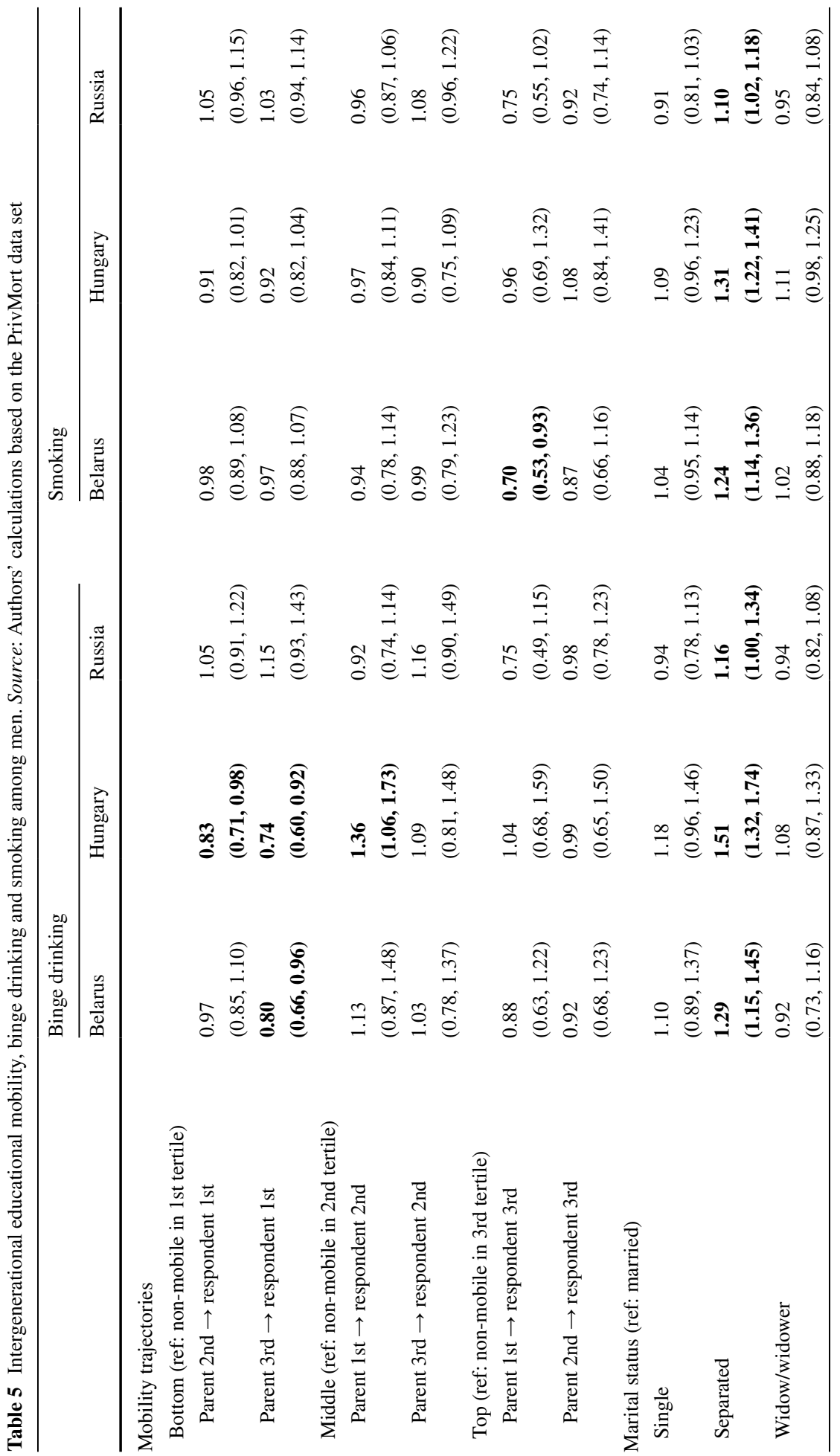




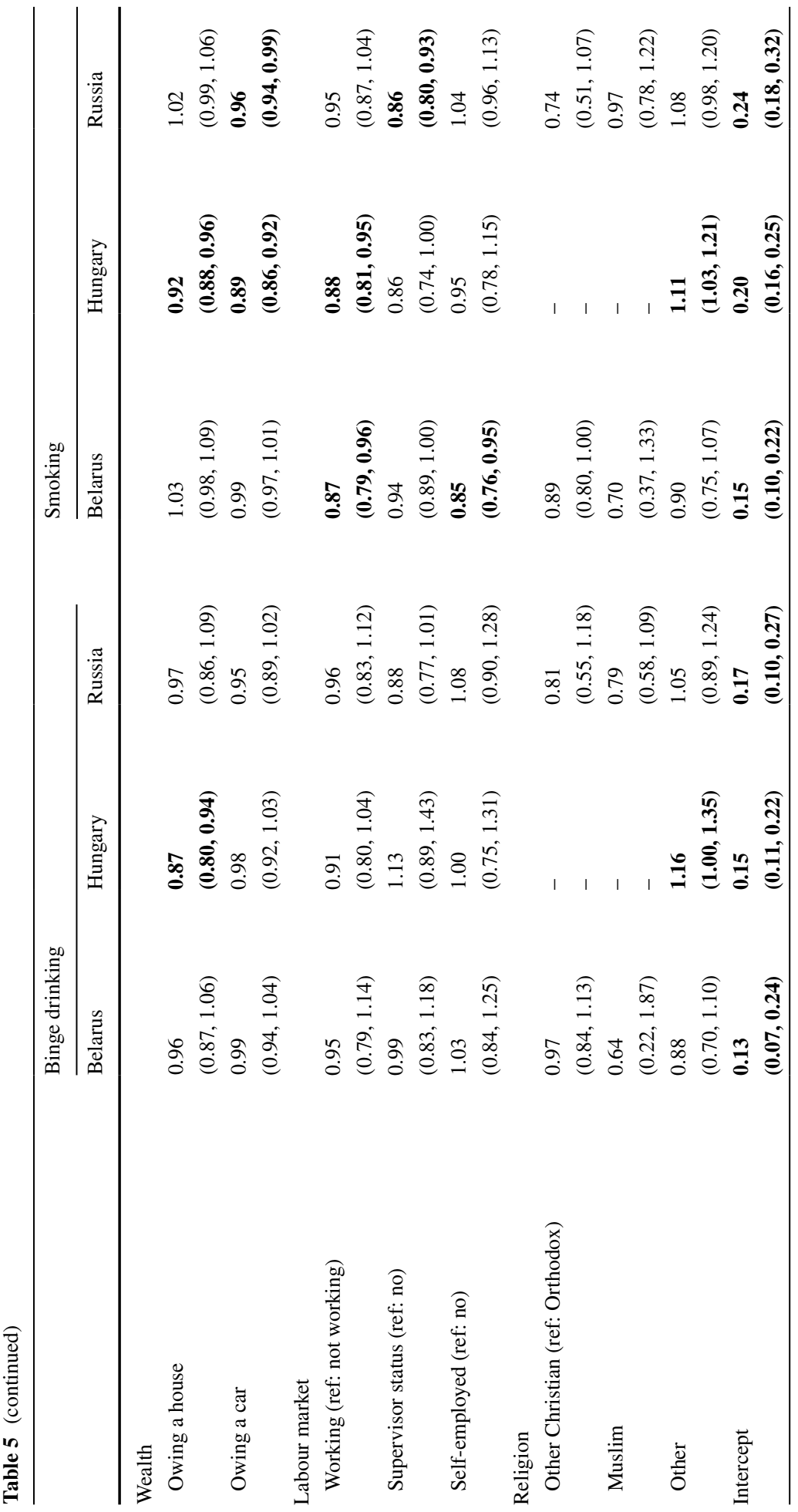




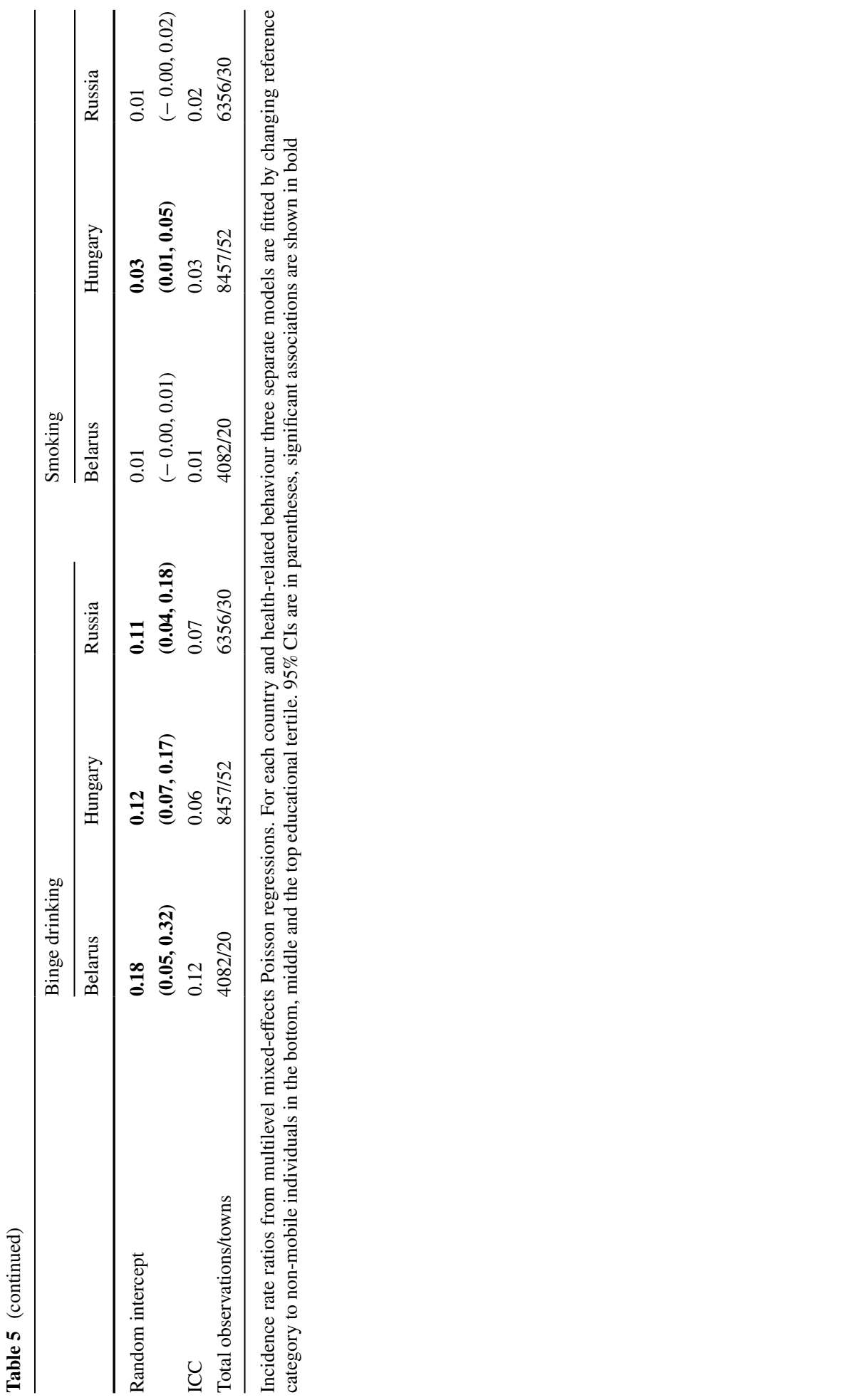




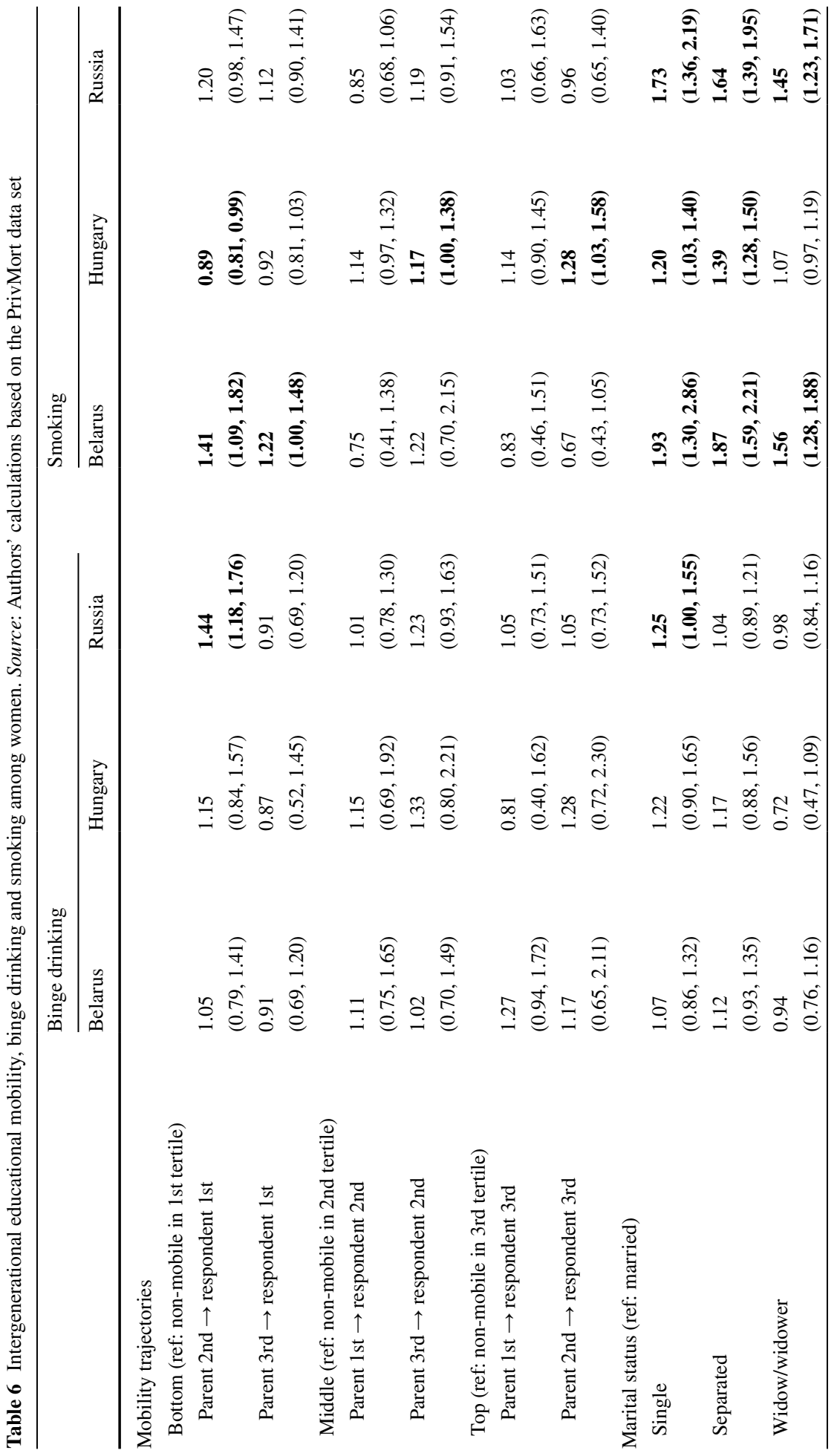




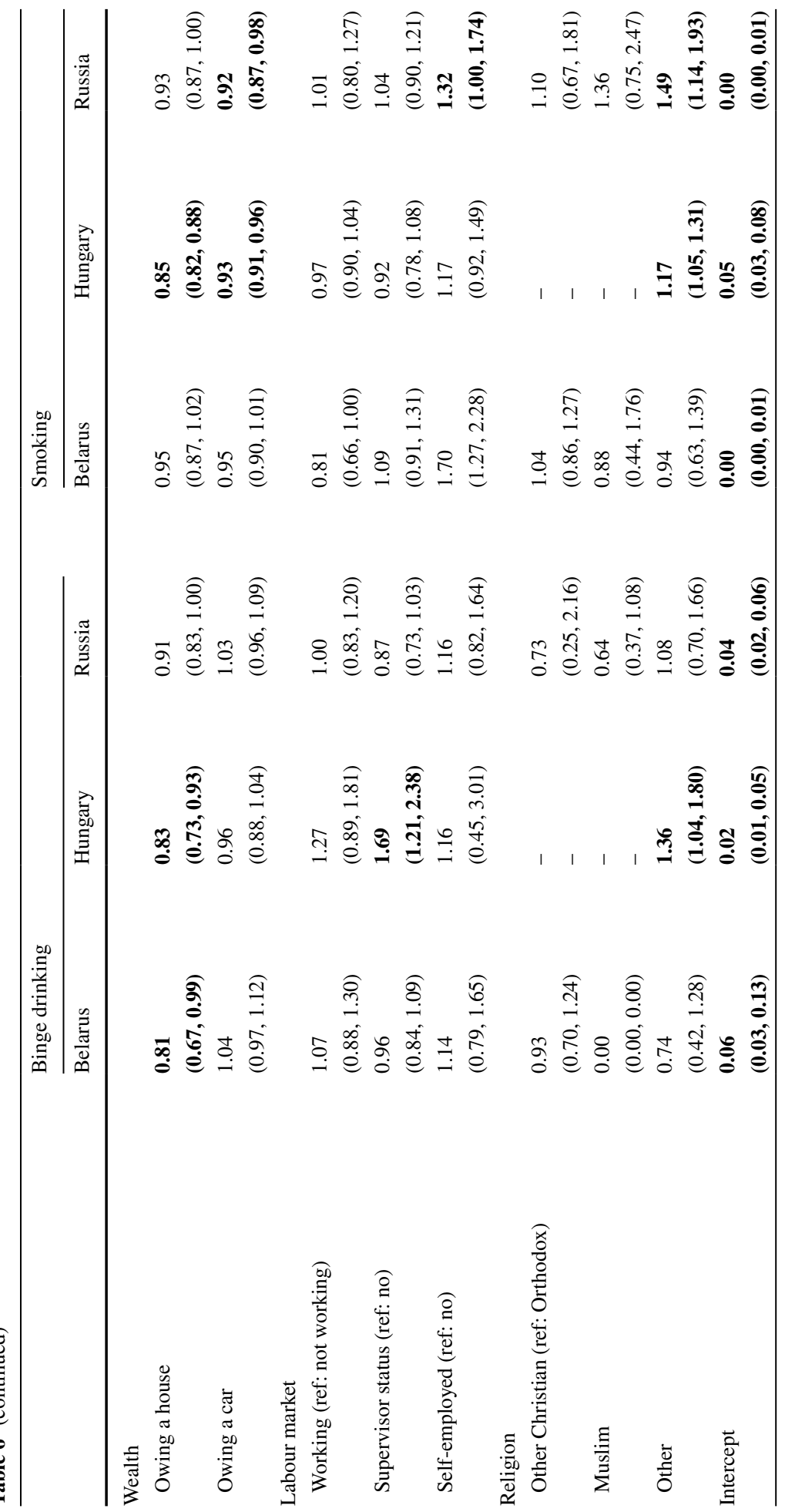




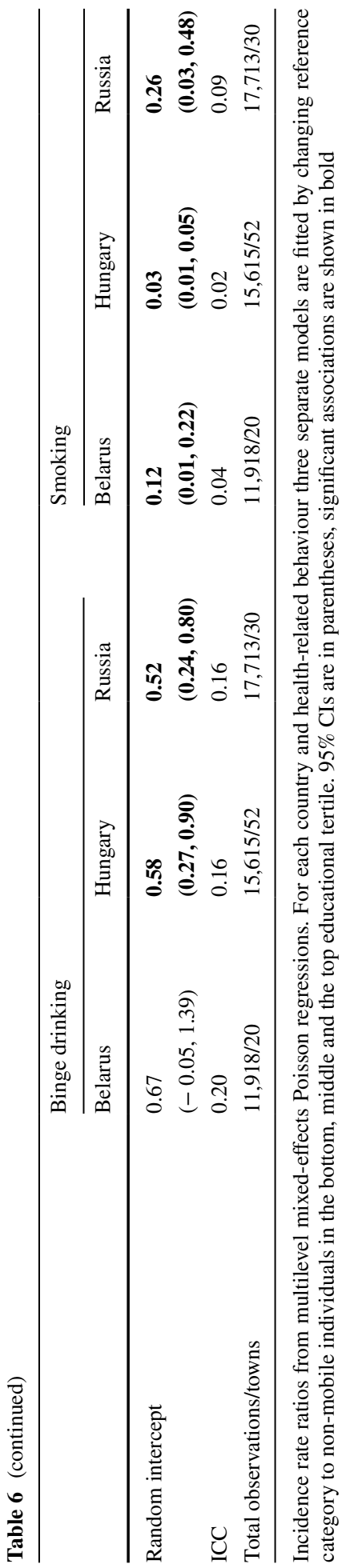


in the bottom tertile of educational attainment whose parents were in the top educational tertile are less likely to binge drink in Belarus (IRR 0.80; 95\% CI 0.66, 0.96) and Hungary (IRR $0.74 ; 95 \%$ CI $0.60,0.92$ ) when compared with intergenerationally non-mobile individuals with a low level of education. In addition, in Hungary, the incidence rate ratio of binge drinking is 0.83 (95\% CI $0.71,0.98$ ) for downwardly mobile men from the middle to the bottom tertile of educational attainment. The latter findings tend to corroborate the accumulation hypothesis on social mobility and health-related behaviours than the Falling from Grace hypothesis. We observe the opposite relationship when looking at women in Russia. Those who are downwardly mobile, from the middle to the bottom educational tertile, have an incidence rate ratio of 1.44 (95\% CI 1.18, 1.76) for binge drinking. This effect is the only significant association that we observe among women for binge drinking and it is in line with the Falling from Grace hypothesis on the negative consequences associated with downward mobility.

Significant associations are also found when considering the links between intergenerational educational mobility and smoking. Upwardly mobile Belarussian men from the lowest to the highest educational tertile are significantly less likely to smoke (OR $0.7095 \%$ CI $0.53,0.93$ ) than non-mobile individuals with the same level of education. The latter is at odds with the dissociative thesis and instead supports a positive effect of upward social mobility on individuals' health-related behaviours. Among women in Belarus downward mobility from the top and the middle educational tertiles in the bottom educational tertile is associated, respectively, with incidence rate ratios of $1.22(95 \%$ CI 1.00, 1.48) and $1.41(95 \%$ CI 1.09, 1.82) for being current smokers. This finding supports the prediction of negative consequences from downward intergenerational mobility. On the other hand, for Hungarian women the findings are more consistent with the accumulation hypothesis. The results suggest that both those who experience downward mobility to the bottom educational tertile from the middle one are less likely to be current smokers, with incidence rate ratios of 0.89 (95\% CI 0.81, 0.99), while those who experience upward mobility to the top educational tertile from the middle one are more likely to be current smokers with incidence rate ratios of 1.28 (95\% CI 1.03, 1.58).

\subsection{Predicted Probabilities}

As suggested in earlier research, findings on inequalities in health should be reported using both relative and absolute measures as presenting only one could mislead as to the magnitude, direction and significance of results (Campos-Matos and Kawachi 2015; King et al. 2012). Figures 3 and 4 show predicted probabilities and corresponding 95\% CIs for binge drinking and smoking for individuals with varying intergenerational educational trajectories averaged across the relevant populations in Belarus, Hungary and Russia. The depicted results suggest that not only are there no systemic and significant risk differences in binge drinking in Belarus and Russia among individuals with different intergenerational mobility trajectories but also there are no major differences in terms of individuals' educational attainment and this health-related behaviour. Confidence intervals for predicted probabilities of individuals with highest educational attainment in all three countries and for both genders overlap with confidence intervals of predicted probabilities for those with the lowest level of educational attainment. Nonetheless, in Hungary we observe that men in the bottom educational tertile with parents in the same level of education have 0.18 (95\% CI $0.15,0.21)$ probability, whereas non-mobile men in the top educational group have 0.11 (95\% CI $0.08,0.13)$ probability of binge drinking. Neither in the top nor in the bottom 
(a)

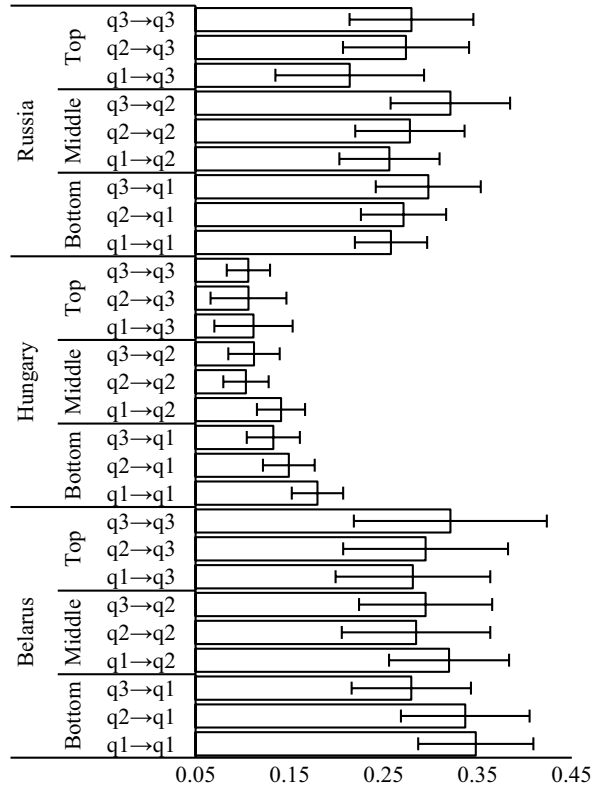

(b)

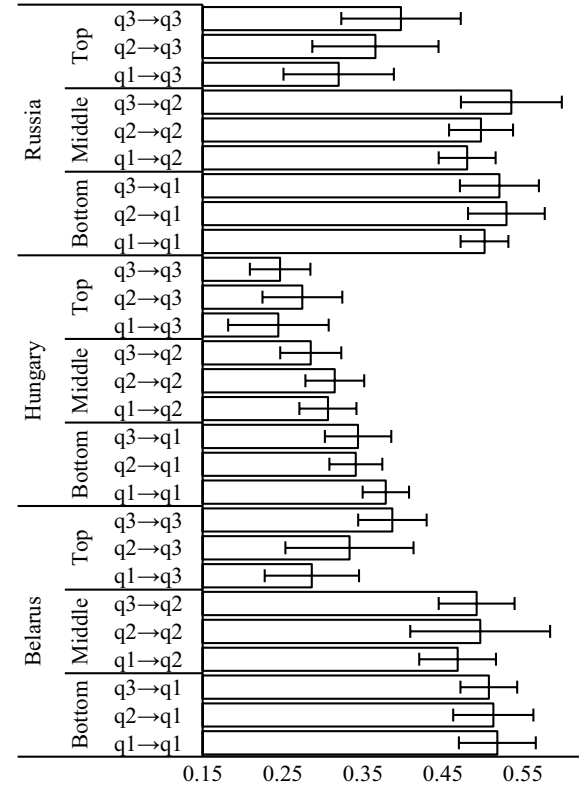

Fig. 3 Predicted probabilities of a binge drinking and $\mathbf{b}$ smoking among men. Notes Error bars represent 95\% CIs. qX $\rightarrow$ qX represent intergenerational trajectories from parental educational tertile to respondents educational tertile. Source: Authors' calculations based on the PrivMort data set

of educational tertiles are individuals' intergenerational educational trajectories associated with their likelihood of binge drinking.

On the other hand, the estimated predicted probabilities in Figs. $3 \mathrm{~b}$ and $4 \mathrm{~b}$ suggest that there is a large educational gradient in smoking in all countries and for both genders and education does have significant association with this health-related behaviour. For instance, in Russia in the top educational tertile non-mobile men (PP $0.5095 \%$ CI 0.47, 0.53) have about 10 percentage points lower risk of smoking than non-mobile individuals in the bottom educational tertile, whereas the least educated and non-mobile women in Hungary (PP $0.2395 \%$ CI $0.21,0.25)$ are 8 percentage points more likely to smoke than non-mobile women in the top educational tertile.

The effect of intergenerational educational mobility on smoking, in most instances is not statistically significant as individuals' likelihood of smoking, when their educational attainment is accounted for, does not vary according to their trajectories of mobility. Nonetheless, for both genders in Belarus we observe a significant association between intergenerational educational mobility and smoking. First, Belarusian men with the highest educational attainment are predicted to have 0.39 (95\% CI 0.34, 0.43) risk of being smokers if they did not experience intergenerational mobility, whereas this risk is only 0.29 (95\% CI $0.23,0.35)$ among those who moved from the lowest to the highest educational tertile. The last effect that we describe is not very large but it is still statistically significant. In terms of association between intergenerational educational mobility and smoking among women, 
(a)

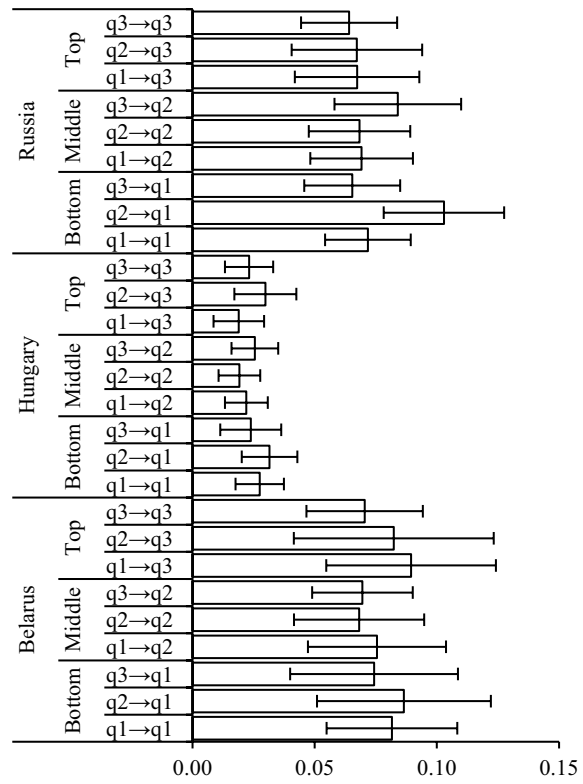

(b)

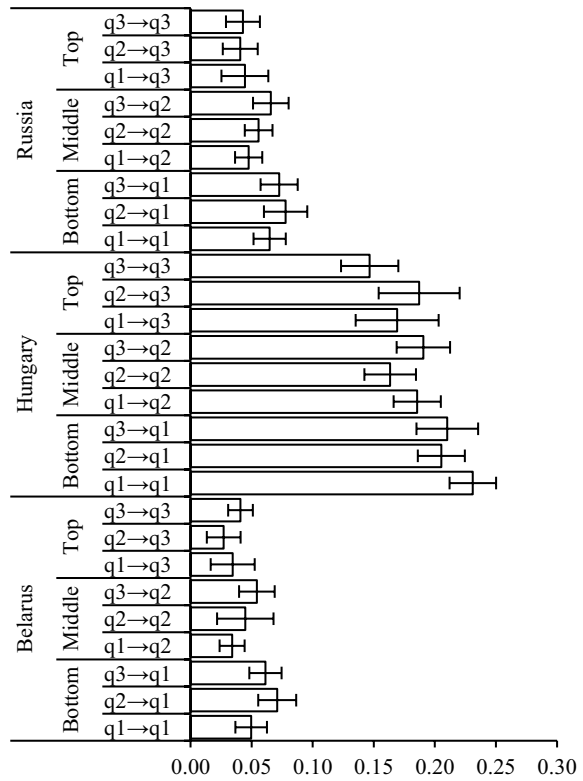

Fig. 4 Predicted probabilities of a binge drinking and $\mathbf{b}$ smoking among women. Notes Error bars represent $95 \%$ CIs. qX $\rightarrow$ qX represent intergenerational trajectories from parental educational tertile to respondents educational tertile. Source: Authors' calculations based on the PrivMort data set

in Belarus downwardly mobile women in the middle educational tertile have 0.05 (95\% CI $0.04,0.07)$ predicted probability of smoking, while upwardly mobile females are estimated to have a risk of $0.03(95 \% \mathrm{CI} 0.02,0.04)$ to be current smokers. Both of these associations support the hypothesis that there are benefits of upward social mobility for health-related behaviours.

\subsection{A Summary of the Results}

Before discussing the findings, we summarise the main results of our analyses. Our findings, in line with the existing literature, show that, adjusting for age, individuals' marital status, wealth, labour market characteristics, and religious denomination are all important explanations of the considered health-related behaviours-binge drinking and smoking. In terms of the main research question of this study on the links between intergenerational social mobility and the outcome variables, we will identify those findings which were common to Belarus, Hungary and Russia and findings which were distinctive in each of these countries. In all three countries both binge drinking and smoking are more closely associated with downward than upward intergenerational mobility. Most effects for intergenerational downward mobility are manifested in relation to binge drinking, while most effects for intergenerational upward mobility are manifested in relation to smoking. One of the findings that stands out is that mobility effects of intergenerational educational attainment are more clearly manifested in Hungary (six incidence rate ratios being significant) and Belarus (four incidence rate ratio being significant) but less so in Russia (only one 
incidence rate ratio being significant). Furthermore, in terms of estimated predicted probabilities, the significant results are only observed in Belarus.

We have also found evidence suggesting gender differences in the links between intergenerational education mobility and health-related behaviours. First, for men four out of five statistically significant mobility effects in terms of incidence rate ratios are observed for binge drinking, while for women five out of six statistically significant mobility effects are observed for smoking. Second, for men all statistically significant effects of downward intergenerational mobility are related with the lower incidence rate ratios of binge drinking and smoking. The reverse is the case for women for whom most statistically significant consequences of downward intergenerational mobility are related to the higher incidence rate ratios of the considered health-related behaviours.

\section{Discussion}

Political, economic and social changes in post-socialist societies during the early to mid1990s have had profound consequences on their health-related behaviours, health outcomes and health care systems (Stuckler et al. 2009). It is likely that the collapse of social welfare regimes in these countries has intensified inequalities among various mobility groups in their access to material and other resources that are important determinants of health-related behaviours and ill-health (Mackenbach 2012). The findings presented in this study indicate that, after controlling for important socio-demographic and socio-economic confounders of binge drinking and smoking, intergenerational mobility in relative educational attainment in Belarus, Hungary and Russia does not exert systemic and consistent associations with health-related behaviours that would be expected with any single existing hypothesis. Depending on the country of analysis, the mode of mobility, the gender of respondents and the type of health-related behaviour, we find support for both the accumulation hypothesis and the Falling from Grace one, as well as those perspectives which predict positive changes in health-related behaviours with upward social mobility. One possibility is that upwardly mobile individuals, compared with non-mobile privileged groups have higher confidence and a sense of control of their own lives and follow healthy lifestyles more consistently. Upwardly mobile individuals may even express a sense of gratitude to the social environment for making the achievement of their present socio-economic advantages possible (Daenekindt et al. 2017).

As shown in the previous section, the consequences of intergenerational mobility in educational attainment on individuals' health-related behaviours are most and least observed, respectively, in Hungary and Russia. An interesting question is what factors can explain the unique patterns in these countries. One explanation for this can be the overall differences in intergenerational social mobility between Hungary and Russia. Recent comparative research in social stratification and mobility indicates that Hungary is one of the least mobile societies in Europe, while Russia, along with other post-Soviet republics, has much higher levels of intergenerational mobility. There are reasons to believe that the effect of individual-level experience of intergenerational social mobility on health is manifested differently depending of the prevalence of social mobility in a society. Assuming that the beneficial effects of intergenerational social mobility are at least partially derived though social comparisons, then, for instance, sense of control and achievements of upwardly mobile individuals might less important if intergenerational social mobility is a widespread phenomenon. Thus experiencing social mobility Hungary might have more significant 
health consequences than experiencing social mobility in more fluid countries like Russia and Belarus (Bukodi et al. 2017; Gugushvili 2017a, b).

It is also important to highlight that we operationalised intergenerational educational mobility employing the "dominance approach" which used the highest level of parental education to determine intergenerational mobility. This contradicts the usual practice in public health literature that measures social mobility separately in relation to father and mother's achieved status. Arguably, one of the main contributions of this article is that in our methodological approach we deviated from more conventional measurement of educational mobility which takes into account only absolute differences in educational qualifications between parents and their children. To compare how the latter operationalisation of intergenerational educational mobility is associated with health-related behaviours, in the unreported analysis we re-estimated associations presented in the main text, but this time with absolute measures of educational mobility.

When we switch to the absolute measure of intergenerational educational mobility we do not find any statistically significant associations in the main analysis. These findings tentatively suggest that the relative measure of intergenerational social mobility could be a more appropriate approach to study the consequences of intergenerational mobility on health-related behaviours. In the latter framework the status syndrome, as a factor in health inequalities (Marmot 2004), should be considered from an intergenerational perspective. If we assume that health-related behaviours are related to the positions that individuals possess in the social hierarchy, then intergenerational mobility must be measured in relation to change in relative position in educational distribution rather than by simple acquisition of formal qualifications by individuals in comparison to their parents. It is likely that individuals do not simply compare their status to that of their parents in absolute or relative terms, but apparently rather to their relative position among their peers than their parents' relative position in their respective generations. It is advisable that future studies on the links between intergenerational social mobility, health-related behaviours and health consider intergenerational relative mobility instead of, or at least along with, absolute mobility measures.

One of the main findings of this study is that both individuals' educational attainment and their intergenerational trajectories exert stronger associations with smoking than with binge drinking, especially when estimated with predicted probabilities. These findings are in line with previous research showing that intergenerational mobility has a stronger effect on daily smoking than for instance with weekly use of alcohol or being heavily intoxicated more than once a month (Glendinning et al. 1994). This is arguably not surprising, given other evidence that smoking in the home influences the likelihood of initiation by adolescents. Besides, there is a widespread, albeit controversial, view that low to moderate levels of alcohol intake might have a protective effect on health (Stockwell et al. 2016), while the healthiest level of tobacco consumption is known to be zero (Marmot 1997).

Furthermore, the observed differences in the links between intergenerational education mobility and health-related behaviours among men and women might suggest that there are gender specific manifestation of mechanisms which link mobility and specific healthrelated behaviours. More specifically the mechanisms predicted by Falling from Grace hypothesis such as elevated levels of distress seem to be are more important for women, while the accumulation perspective of the effects of mobility, which implies that individuals' previous advantageous social conditions can protect them from various adverse behaviours, are more important for men. One of the reasons of these gender differences could be that the considered societies are still quite patriarchal and downwardly mobile men might maintain stronger links with their parents than do downwardly mobile daughters (Verdery 
1994). This in turn can be manifested in more severe consequences of downward intergenerational educational mobility for women than for men.

Our study has a number of limitations. First, we detect more significant associations when the results are presented as incidence rate ratios than as predicted probabilities. The differences between relative (incidence rate ratios) and absolute (predicted probabilities) measures in social science research are a well-known phenomenon. If a relative measure is invariant to equiproportionate changes, an absolute measure is invariant to uniform changes in an outcome variable (Allanson and Petrie 2013). Therefore, deriving contradictory results is not entirely unexpected and use of only incidence rate ratios or predicted probabilities can be misleading in terms of testing hypotheses on accumulation, Falling from Grace, and positive consequence of upward intergenerational mobility (CamposMatos and Kawachi 2015; King et al. 2012). Our analytical approach helps us not to overinterpret significant coefficients that do not show systematic patterns across different estimation measures.

The PrivMort data set, although unique in many ways, does not provide nationally representative samples and hence our findings cannot be generalised to each country's entire populations. Data on parental education is retrospective and might be marred by respondents' recall bias. Although earlier research does not find convincing evidence that individuals' health-related behaviours can significantly affect their prospects of social mobility, the association between mobility and health-related behaviours may be bidirectional (see Blane et al. 1993; West 1991). Furthermore, our operationalisation of intergenerational mobility is based only on respondents' and their parents' educational attainment. The PrivMort data set does not include information about the measures of income, while occupational variable for respondents' parents is only available if they were gainfully employed in the 1980s or thereafter. This does not allow us to identify if social mobility in terms of occupational social class or income has any effect on individuals' propensity of binge drinking and smoking. Existing research suggests that various indicators of socioeconomic status, both in terms of individuals' origins and their destinations, can have different meanings and preferably must be accounted for in future research (Bukodi and Goldthorpe 2013). Lastly, our results leave it open as to whether the exact mechanism linking intergenerational mobility in relative educational attainment, binge drinking and smoking is based on psychosocial, peer group effects or some other processes.

\section{Conclusion}

We found that intergenerational educational mobility, measured by means of the prevalence of specified qualifications in parental and offspring generations, has varying association with binge drinking and smoking and the strength and direction of these effects depend on the country of analysis, the mode of mobility, the gender of respondents and the type of health-related behaviour. Our findings might be conditioned by the unique character of the three post-communist societies-Belarus, Hungary and Russia-which exhibit both distinct patterns of social mobility and histories of widespread binge drinking and tobacco consumption. Our tentative finding that the relative measure of intergenerational educational mobility has a stronger association with binge drinking and smoking than the absolute measure of mobility also suggests that the expansion of educational systems might have a limited effect on health-related behaviours. On the other hand, if we assume that the effect of intergenerational educational mobility on health-related behaviours is partially 
channelled through stress associated with individuals' labour market circumstances, then the improvement of employment possibilities and individuals' work environment might be a more robust way to address problems related to binge drinking and smoking.

Funding This study was funding by the European Research Council. Project full title: Privatisation and Mortality in Post-Communism: A Multi-Level Indirect Demographic Analysis. Grant Agreement No. 269036.

\section{Compliance with Ethical Standards}

Conflict of interest The authors declare that they have no conflict of interests.

Ethics Approval The survey used in this study has been approved by the University of Cambridge Department of Sociology ethics committee.

Open Access This article is distributed under the terms of the Creative Commons Attribution 4.0 International License (http://creativecommons.org/licenses/by/4.0/), which permits unrestricted use, distribution, and reproduction in any medium, provided you give appropriate credit to the original author(s) and the source, provide a link to the Creative Commons license, and indicate if changes were made.

\section{References}

Allanson, P., \& Petrie, D. (2013). On the choice of health inequality measure for the longitudinal analysis of income-related health inequalities. Health Economics, 22(3), 353-365. https://doi.org/10.1002 /hec. 2803 .

Ayer, L. A., Harder, V. S., Rose, G. L., \& Helzer, J. E. (2011). Drinking and stress: An examination of sex and stressor differences using IVR-based daily data. Drug and Alcohol Dependence, 115(3), 205-212. https://doi.org/10.1016/j.drugalcdep.2010.10.022.

Azarova, A., Irdam, D., Gugushvili, A., Fazekas, M., Scheiring, G., Horvat, P., et al. (2017). The effect of rapid privatisation on mortality in mono-industrial towns in post-Soviet Russia: A retrospective cohort study. The Lancet Public Health, 2(5), e231-e238. https://doi.org/10.1016/S2468-2667(17)30072-5.

Bartley, M., \& Plewis, I. (2007). Increasing social mobility: An effective policy to reduce health inequalities. Journal of the Royal Statistical Society. Series A: Statistics in Society, 170(2), 469-481. https:// doi.org/10.1111/j.1467-985x.2006.00464.x.

Blane, D., Davey Smith, G., \& Bartley, M. (1993). Social selection: what does it contribute to social class differences in health? Sociology of Health and Illness, 15(1), 1-15. https://doi.org/10.1111/1467-9566 .ep11343777.

Bobak, M., Mckee, M., Rose, R., \& Marmot, M. (1999). Alcohol consumption in a national sample of the Russian population. Addiction, 94(6), 857-866. https://doi.org/10.1046/j.1360-0443.1999.9468579.x.

Boyle, P. J., Norman, P., \& Popham, F. (2009). Social mobility: Evidence that it can widen health inequalities. Social Science and Medicine, 68(10), 1835-1842. https://doi.org/10.1016/j.socscimed.2009 .02 .051 .

Breen, R., Luijkx, R., Müller, W., \& Pollak, R. (2009). Nonpersistent inequality in educational attainment: Evidence from eight European countries. The American Journal of Sociology, 114(5), 1475-1521. http ://www.jstor.org/stable/10.1086/595951.

Bukodi, E., \& Goldthorpe, J. H. (2013). Decomposing "social origins": The effects of parents' class, status, and education on the educational attainment of their children. European Sociological Review, 29(5), 1024-1039. https://doi.org/10.1093/esr/jcs079.

Bukodi, E., \& Goldthorpe, J. H. (2016). Educational attainment-Relative or absolute-As a mediator of intergenerational class mobility in Britain. Research in Social Stratification and Mobility, 43, 5-15. https://doi.org/10.1016/j.rssm.2015.01.003.

Bukodi, E., Paskov, M., \& Nolan, B. (2017). Intergenerational class mobility in Europe: A new account and an old story (INET Oxford working paper nos. 2017-3). Oxford. 
Burrows, R., \& Nettleton, S. (1995). Going against the grain: smoking and "heavy" drinking amongst the British middle classes. Sociology of Health and Illness, 17(5), 668-680. https://doi.org/10.1111/1467 -9566.ep10932149.

Campos-Matos, I., \& Kawachi, I. (2015). Social mobility and health in European countries: Does welfare regime type matter? Social Science and Medicine, 142, 241-248. https://doi.org/10.1016/j.socscime d.2015.08.035.

Cardano, M., Costa, G., \& Demaria, M. (2004). Social mobility and health in the Turin longitudinal study. Social Science and Medicine, 58(8), 1563-1574. https://doi.org/10.1016/S0277-9536(03)00354-X.

Chan, T. W. (2017). Social mobility and the wellbeing of individuals (working paper no. 17-01). London.

Chetty, R., Grusky, D., Hell, M., Hendren, N., Manduca, R., \& Narang, J. (2017). The fading American dream: Trends in absolute income mobility since 1940. Science, 356(6336), 398-406. https://doi. org/10.1126/science.aal4617.

Childs, E., \& de Wit, H. (2010). Effects of acute psychosocial stress on cigarette craving and smoking. Nicotine and Tobacco Research, 12(4), 449-453. https://doi.org/10.1093/ntr/ntp214.

Cockerham, W. C. (2000). Health lifestyles in Russia. Social Science and Medicine, 51(9), 1313-1324. http s://doi.org/10.1016/S0277-9536(00)00094-0.

Cockerham, W. C., Hinote, B. P., \& Abbott, P. (2006). Psychological distress, gender, and health lifestyles in Belarus, Kazakhstan, Russia, and Ukraine. Social Science and Medicine, 63, 2381-2394. https://doi. org/10.1016/j.socscimed.2006.06.001.

D'Arcy, C., \& Gardiner, L. (2017). The generation of wealth: Asset accumulation across and within cohorts. London, UK: Resolution Foundation and Intergenerational Commission.

Daenekindt, S. (2016). The experience of social mobility: Social isolation, utilitarian individualism, and social disorientation. Social Indicators Research. https://doi.org/10.1007/s11205-016-1369-3.

Daenekindt, S., van der Waal, J., \& de Koster, W. (2017). Social mobility and political distrust: cults of gratitude and resentment? Acta Politica. https://doi.org/10.1057/s41269-017-0050-4.

Dahl, E. (1996). Social mobility and health: cause or effect? BMJ, 313(7055), 435-436. https://doi. org/10.1136/bmj.313.7055.435.

Erikson, R. (2006). Social class assignment and mortality in Sweden. Social Science and Medicine, 62(9), 2151-2160. https://doi.org/10.1016/j.socscimed.2005.09.009.

Faresjö, T., Svärdsudd, K., \& Tibblin, G. (1994). Social mobility and health in a prospective study of middle-aged men. Scandinavian Journal of Public Health, 22(2), 86-89. https://doi.org/10.1177/14034948 9402200202.

Fiatal, S., Tóth, R., Moravcsik-Kornyicki, Á., Kósa, Z., Sándor, J., McKee, M., et al. (2016). High prevalence of smoking in the roma population seems to have no genetic background. Nicotine and Tobacco Research, 18(12), 2260-2267. https://doi.org/10.1093/ntr/ntw161.

Forey, B., Hamling, J., Hamling, J., Thornton, A., \& Lee, P. (2013). International smoking statistics: A collection of worldwide historical data: Hungary. Sutton, UK: Hungary. P. N. Lee Statistics and Computing Ltd.

Gerber, T. P., \& Hout, M. (1995). Educational stratification in Russia during the soviet period. The American Journal of Sociology, 101(3), 611-660. http://www.jstor.org/stable/2781996.

Gilmore, A. B., McKee, M., \& Rose, R. (2001). Prevalence and determinants of smoking in Belarus: A national household survey, 2000. European Journal of Epidemiology, 17(3), 245-253. https://doi. org/10.1023/A:1017999421202.

Giovino, G. A., Henningfield, J. E., Tomar, S. L., Escobedo, L. G., \& Slade, J. (1995). Epidemiology of tobacco use and dependence. Epidemiologic Reviews, 17(1), 48-65. https://doi.org/10.1093/oxfordjo urnals.epirev.a036185.

Glendinning, A., Shucksmith, J., \& Hendry, L. (1994). Social class and adolescent smoking behaviour. Social Science and Medicine, 38(10), 1449-1460. https://doi.org/10.1016/0277-9536(94)90283-6.

Goldthorpe, J. H. (2014). The role of education in intergenerational social mobility: Problems from empirical research in sociology and some theoretical pointers from economics. Rationality and Society, 26(3), 265-289. https://doi.org/10.1177/1043463113519068.

Gugushvili, A. (2015). Economic liberalization and intergenerational mobility in occupational status. Comparative Sociology, 14(6), 790-820. https://doi.org/10.1163/15691330-12341368.

Gugushvili, A. (2016a). Intergenerational objective and subjective mobility and attitudes towards income differences: Evidence from transition societies. Journal of International and Comparative Social Policy, 32(3), 199-219. https://doi.org/10.1080/21699763.2016.1206482.

Gugushvili, A. (2016b). Intergenerational social mobility and popular explanations of poverty: A comparative perspective. Social Justice Research, 29(4), 402-428. https://doi.org/10.1007/s11211-016-0275-9. 
Gugushvili, A. (2017a). Political democracy, economic liberalization, and macro-sociological models of intergenerational mobility. Social Science Research, 66, 58-81. https://doi.org/10.1016/j.ssresear ch.2017.06.003.

Gugushvili, A. (2017b). Change or continuity? Intergenerational social mobility and post-communist transition. Research in Social Stratification and Mobility, 52, 59-71. https://doi.org/10.1016/j.rssm.2017.10.004.

Gugushvili, A., Bukodi, E., \& Goldthorpe, J. H. (2017). The direct effect of social origins on social mobility chances: "glass floors" and "glass ceilings" in Britain. European Sociological Review, 33(2), 305-316. https://doi.org/10.1093/esr/jcx043.

Gugushvili, A., McKee, M., Azarova, A., Murphy, M., Irdam, D., \& King, L. (2018). Parental transmission of smoking among middle-aged and older populations in Russia and Belarus. International Journal of Public Health. https://doi.org/10.1007/s00038-017-1068-0

Hart, C. L., Smith, G. D., \& Blane, D. (1998). Social mobility and 21 year mortality in a cohort of Scottish men. Social Science and Medicine, 47(8), 1121-1130. https://doi.org/10.1016/S0277-9536(98)0006 1-6.

Hart, C. L., Smith, G. D., Upton, M. N., \& Watt, G. C. M. (2009). Epidemiology: Alcohol consumption behaviours and social mobility in men and women of the midspan family study. Alcohol and Alcoholism, 44(3), 332-336. https://doi.org/10.1093/alcalc/agn125.

Hemmingsson, T., Lundberg, I., \& Diderichsen, F. (1999). The roles of social class of origin, achieved social class and intergenerational social mobility in explaining social-class inequalities in alcoholism among young men. Social Science and Medicine, 49(8), 1051-1059. https://doi.org/10.1016/S027 7-9536(99)00191-4.

Heraclides, A., \& Brunner, E. (2010). Social mobility and social accumulation across the life course in relation to adult overweight and obesity: The Whitehall II study. Journal of Epidemiology and Community Health, 64(8), 714-719. https://doi.org/10.1136/jech.2009.087692.

Higher Education in Europe. (1977). Hungary: The expansion of higher education and its determining factors. Higher Education in Europe, 2(6), 21-24. https://doi.org/10.1080/0379772770020608.

Houle, J. N. (2011). The psychological impact of intragenerational social class mobility. Social Science Research, 40(3), 757-772. https://doi.org/10.1016/j.ssresearch.2010.11.008.

Houle, J. N., \& Martin, M. A. (2011). Does intergenerational mobility shape psychological distress? Sorokin revisited. Research in Social Stratification and Mobility, 29(2), 193-203. https://doi.org/10.1016/j.rssm .2010.11.001.

Irdam, D., King, L., Gugushvili, A., Azarova, A., Fazekas, M., Scheiring, G., et al. (2016). Mortality in transition: Study protocol of the PrivMort project, a multilevel convenience cohort study. BMC Public Health, 16(1), 672. https://doi.org/10.1186/s12889-016-3249-9.

Iveson, M. H., \& Deary, I. J. (2017). Intergenerational social mobility and subjective wellbeing in later life. Social Science and Medicine, 188, 11-20. https://doi.org/10.1016/j.socscimed.2017.06.038.

Jefferis, B., Graham, H., Manor, O., \& Power, C. (2003). Cigarette consumption and socio-economic circumstances in adolescence as predictors of adult smoking. Addiction, 98(12), 1765-1772. https://doi. org/10.1111/j.1360-0443.2003.00552.x.

Jefferis, B. J. M. H., Power, C., Graham, H., \& Manor, O. (2004). Effects of childhood socioeconomic circumstances on persistent smoking. American Journal of Public Health, 94(2), 279-285. https://doi. org/10.2105/AJPH.94.2.279.

Johnson, V., Currie, G., \& Stanley, J. (2010). Measures of disadvantage: Is car ownership a good indicator? Social Indicators Research, 97(3), 439-450. https://doi.org/10.1007/s11205-009-9510-1.

Jonsson, F., Sebastian, M. S., Hammarström, A., \& Gustafsson, P. E. (2017). Intragenerational social mobility and functional somatic symptoms in a northern Swedish context: Analyses of diagonal reference models. International Journal for Equity in Health, 16(1), 1-10. https://doi.org/10.1186/s12939-0160499-1.

Karvonen, S., Rimpela, A. H., \& Rimpela, M. K. (1999). Social mobility and health related behaviours in young people. Journal of Epidemiology and Community Health, 53(4), 211-217. https://doi. org/10.1136/jech.53.4.211.

King, N. B., Harper, S., \& Young, M. E. (2012). Use of relative and absolute effect measures in reporting health inequalities: Structured review. BMJ, 345(sep03 1), e5774-e5774. https://doi.org/10.1136/bmj. e5774.

Kouvonen, A. (2005). Work stress, smoking status, and smoking intensity: an observational study of 46190 employees. Journal of Epidemiology and Community Health, 59(1), 63-69. https://doi.org/10.1136/ jech.2004.019752.

Levin, J. S. (1994). Religion and health: Is there an association, is it valid, and is it causal? Social Science and Medicine, 38(11), 1475-1482. https://doi.org/10.1016/0277-9536(94)90109-0. 
Li, Y., Savage, M., \& Warde, A. (2008). Social mobility and social capital in contemporary Britain. The British Journal of Sociology, 59(3), 391-411. https://doi.org/10.1111/j.1468-4446.2008.00200.x.

Liang, Y., \& Lu, P. (2014). Effect of occupational mobility and health status on life satisfaction of Chinese residents of different occupations: logistic diagonal mobility models analysis of cross-sectional data on eight Chinese provinces. International Journal for Equity in Health, 13(1), 15. https://doi.org/10.1186 /1475-9276-13-15.

Lippényi, Z., \& Gerber, T. P. (2016). Inter-generational micro-class mobility during and after socialism: The power, education, autonomy, capital, and horizontal (PEACH) model in Hungary. Social Science Research, 58, 80-103. https://doi.org/10.1016/j.ssresearch.2015.08.010.

Mackenbach, J. P. (2012). The persistence of health inequalities in modern welfare states: The explanation of a paradox. Social Science and Medicine, 75(4), 761-769. https://doi.org/10.1016/j.socscimed.2012 .02 .031 .

Marmot, M. (1997). Inequality, deprivation and alcohol use. Addiction. https://doi.org/10.1111/j.1360-0443 .1997.tb03391.x.

Marmot, M. (2004). Status syndrome. London: Bloomsbury.

Marmot, M. (2005). Social determinants of health inequalities. Lancet, 365(9464), 1099-1104. https://doi. org/10.1016/S0140-6736(05)71146-6.

Newman, K. S. (1999). Falling from Grace: Downward mobility in the age of affluence. Berkeley: University of California Press.

Nicklett, E. J., \& Burgard, S. A. (2009). Downward social mobility and major depressive episodes among Latino and Asian-American immigrants to the United States. American Journal of Epidemiology, 170(6), 793-801. https://doi.org/10.1093/aje/kwp192.

Paavola, M., Vartiainen, E., \& Haukkala, A. (2004). Smoking from adolescence to adulthood. European Journal of Public Health, 14(4), 417-421. https://doi.org/10.1093/eurpub/14.4.417.

Padyab, M., \& Norberg, M. (2014). Socioeconomic inequalities and body mass index in Västerbotten County, Sweden: A longitudinal study of life course influences over two decades. International Journal for Equity in Health, 13(1), 35. https://doi.org/10.1186/1475-9276-13-35.

Pomerleau, J., Gilmore, A., McKee, M., Rose, R., \& Haerpfer, C. W. (2004). Determinants of smoking in eight countries of the former Soviet Union: Results from the Living Conditions. Lifestyles and Health Study. Addiction, 99(12), 1577-1585. https://doi.org/10.1111/j.1360-0443.2004.00885.x.

Pomerleau, J., Mckee, M., Rose, R., Haerpfer, C. W., Rotman, D., \& Tumanov, S. (2008). Hazardous alcohol drinking in the former Soviet Union: A cross-sectional study of eight countries. Alcohol and Alcoholism, 43(3), 351-359. https://doi.org/10.1093/alcalc/agm167.

Poulton, R., Caspi, A., Milne, B. J., Thomson, W. M., Taylor, A., Sears, M. R., et al. (2002). Association between children's experience of socioeconomic disadvantage and adult health: A life-course study. The Lancet, 360(9346), 1640-1645. https://doi.org/10.1016/S0140-6736(02)11602-3.

Power, C., Matthews, S., \& Manor, O. (1996). Inequalities in self rated health in the 1958 birth cohort: Lifetime social circumstances or social mobility? BMJ. British Medical Journal, 313(7055), 449-453. http s://doi.org/10.1136/bmj.313.7055.449.

Raftery, A. E., \& Hout, M. (1993). Maximally maintained inequality: Expansion, reform, and opportunity in Irish education, 1921-75. Sociology of Education, 66(1), 41-62. http://www.jstor.org/stable/2112784.

Reitzel, L. R., Mazas, C. A., Cofta-Woerpel, L., Li, Y., Cao, Y., Businelle, M. S., et al. (2010). Subjective social status affects smoking abstinence during acute withdrawal through affective mediators. Addiction, 105(5), 928-936. https://doi.org/10.1111/j.1360-0443.2009.02875.x.

Ritterman, M. L., Fernald, L. C., Ozer, E. J., Adler, N. E., Gutierrez, J. P., \& Syme, S. L. (2009). Objective and subjective social class gradients for substance use among Mexican adolescents. Social Science and Medicine, 68(10), 1843-1851. https://doi.org/10.1016/j.socscimed.2009.02.048.

Shkolnikov, V. M. (2006). The changing relation between education and life expectancy in central and eastern Europe in the 1990s. Journal of Epidemiology and Community Health, 60(10), 875-881. https:// doi.org/10.1136/jech.2005.044719.

Steptoe, A., Wardle, J., Pollard, T. M., Canaan, L., \& Davies, G. J. (1996). Stress, social support and healthrelated behavior: A study of smoking, alcohol consumption and physical exercise. Journal of Psychosomatic Research, 41(2), 171-180. https://doi.org/10.1016/0022-3999(96)00095-5.

Stockwell, T., Zhao, J., Panwar, S., Roemer, A., Naimi, T., \& Chikritzhs, T. (2016). Do "moderate" drinkers have reduced mortality risk? A systematic review and meta-analysis of alcohol consumption and allcause mortality. Journal of Studies on Alcohol and Drugs, 77(2), 185-198. https://doi.org/10.15288/ jsad.2016.77.185.

Stuckler, D., King, L., \& McKee, M. (2009). Mass privatisation and the post-communist mortality crisis: A cross-national analysis. The Lancet, 373(9), 399-407. https://doi.org/10.1016/S0140-6736(09)6000 $5-2$. 
Szucs, S., Sárváry, A., McKee, M., \& Ádány, R. (2005). Could the high level of cirrhosis in central and eastern Europe be due partly to the quality of alcohol consumed? An exploratory investigation. Addiction, 100(4), 536-542. https://doi.org/10.1111/j.1360-0443.2005.01009.x.

Titma, M., \& Roots, A. (2006). Intragenerational mobility in successor states of the USSR. European Societies, 8(4), 493-526. https://doi.org/10.1080/14616690500342618.

Tumen, S., \& Zeydanli, T. (2014). Home ownership and job satisfaction. Social Indicators Research, 117(1), 165-177. https://doi.org/10.1007/s11205-013-0338-3.

Verdery, K. (1994). From parent-state to family patriarchs: gender and nation in contemporary Eastern Europe. East European Politics and Societies, 8(2), 225-255. https://doi.org/10.1177/088832549400 8002002.

West, P. (1991). Rethinking the health selection explanation for health inequalities. Social Science and Medicine, 32(4), 373-384. https://doi.org/10.1016/0277-9536(91)90338-D.

Zhang, X., \& Hwang, S. S. (2007). The micro consequences of macro-level social transition: How did Russians survive in the 1990s? Social Indicators Research, 82(2), 337-360. https://doi.org/10.1007/s112 05-006-9037-7. 